\title{
Technology and Democracy: Three Lessons from Brexit
}

\author{
Luciano Floridi ${ }^{1}$
}

Published online: 2 August 2016

(C) Springer Science+Business Media Dordrecht 2016

The British referendum in favour of the exit from the European Union, known as Brexit, has been described as

"probably the most disastrous single event in British history since the second world war" (Wolf, 2016).

I agree. But, as the phrase goes, never waste a good crisis, especially in terms of understanding what went wrong, and what could be avoided in the future. There are many lessons that can be learnt from Brexit. Three seem to be particularly relevant when it comes to the relationship between democracy and digital technologies.

First lesson. It is common to consider representative democracy a compromise due to practical constraints. True democracy would be direct, being based on unmediated, constant, and universal participation of all citizens in political matters. If we lived in a small community where everyone could learn about common issues, participate in their debate, identify and discuss the available options and their consequences, their respective advantages and disadvantages, and eventually reach a reasonable consensus, informed and tolerant, on what to do, based on universal suffrage and by a majority of individual voting, then that would be a true democracy. Unfortunately, we are many, indeed way too many, and delegation of political power is a necessary if minor evil. As John Stuart Mill put it quite eloquently:

"[...] the only government which can fully satisfy all the exigencies of the social state is one in which the whole people participate [...] nothing less can be ultimately desirable, than the admission of all to a share in the sovereign power of the state. But since all cannot, in a community exceeding a single small town, participate personally on any but some very minor portions of the public business,

Luciano Floridi

luciano.floridi@oii.ox.ac.uk

1 Oxford Internet Institute, University of Oxford, 1 St Giles, Oxford OX1 3JS, UK 
it follows that the ideal type of a perfect government must be representative." (Mill 1861), p. 69.

It is the myth of the city-state, and especially of Athens. According to some estimates, during the fourth century $\mathrm{BC}$, there might have been about 100,000 people belonging to citizen families in Athens, with about 30,000 adult male citizens who were entitled to vote in the assembly (Thorley 2004). Politics could easily be everyone's business.

The compromise in favour of a representative democracy has seemed inevitable for centuries, until the arrival of the Internet. Old "passive" media, especially the press, the radio, and the television, have accentuated the positive aspects (information and public debate) and the negative ones (misinformation and populism) of representative democracy. But today - the argument continues - online interactivity could do more than merely polarise the good and the bad. It seems to promise a new sort of democratic, digital agora, which could finally enable the regular, direct involvement of every interested citizen. It is the same promise made by the referendum instrument. In either case, voters are asked directly what should be done. The only task left to the political, administrative, and technical class would be that of implementing the popular decision. Politicians would be civil servants in a very literal sense. It may seem a good idea. In reality it is not, because it is based on a dangerous confusion. Let me explain.

There are two main interpretations of democracy today. One is procedural (see for example Schumpeter or Kelsen). According to it

"[a democratic regime is] first and foremost a set of procedural rules for arriving at collective decisions in a way which accommodates and facilitates the fullest possible participation of interested parties."(Bobbio and Bellamy 1987), p. 19.

The other, slightly more popular in the past, is substantial and maintains that

"[a democratic regime is] Government by the people, where liberty, equality and fraternity are secured to the greatest possible degree and in which human capacities are developed to the utmost, by means including free and full discussion of common problems and interests." (Pennock 1979), p. 7.

Proceduralism is about what rules (to be followed) define a democracy; substantialism is about what values (to be implemented) define a democracy. The logical space may seem to be exhausted by these two alternatives, roughly focusing on either form or content. Yet, there is a third possible interpretation of democracy, which I would like to call structural. According to it, a democratic regime is one in which there is a clear separation between those who hold political power (understood as sovereignty) and can delegate it legitimately by voting, namely the voting-age citizens, and those who are delegated such political power and can exercise their mandate by governing transparently, accountably, and for as long as they are legitimately empowered. To put it simply, according to a structuralist view, a democratic regime is not merely a way of exercising power but first and foremost a way of organising it: those who hold the power do not exercise it but delegate it to those who exercise it but do not hold it. From such a structural perspective, representative democracy is not a compromise but actually the best form of democracy. Considering it to be less preferable 
than its direct version means confusing procedural with structural aspects in the management of power.

To understand the confusion, consider that a dictatorship is any regime in which those who hold the power exercise it by legitimising themselves. This identity between source, legitimation, and exercise of political power is very dangerous, not because it is necessarily malicious in itself, but because it is a very brittle mechanism with no resilience, unable to recover from any mistake. This is why theocratic regimes are coherent in thinking that they do not need to be democratic: they believe themselves to be based on ultimate truths and infallibility. If God is the dictator, no democracy is required because no mistake is made, so no risk and error management is needed, and hence, no safe separation between possession and exercise of political power is required. Of course, in the real world, political errors happen very often, sometimes with far-reaching and disastrous consequences. Their tragic possibility is unavoidable both because of human fallibility and weakness and because politics constantly deals with new unknowns, open problems to which new solutions need to be found, often by designing them under time pressure, with limited resources, and by coping with conflicting requirements. Therefore, even the best and most enlightened form of dictatorship (despotism, in Mill's words) makes a lot of serious mistakes. However, this is not yet the real, deepest trouble, which is rather a dictatorship's very dangerous inability to fix them. This is not the case in a representative democracy, where those who do not exercise political power but ultimately are the legitimising source of it can more easily control and correct the course of actions taken by those who have been elected. A representative democracy is not the best regime to deliver successful political decisions, it is the best regime to avoid the misuse of power, manage risks, and rectify errors, because it is more robust, resilient, and self-recovering than any other forms of government, including direct democracy.

Thus, from a structuralist perspective, the separation between sovereignty (political power that can be legitimately delegated) and governance (political power that is legitimately delegated, temporarily, conditionally, and accountably, and that can be equally legitimately withdrawn) is vital. Through the centuries, we have realised that the best way of achieving such a separation is by giving power to all political stakeholders, that is, by giving the right to vote to anyone who is mature enough (age limit) and is affected by the exercise of the delegated political power (universal suffrage). So, sovereignty is purposefully diluted among as many adult citizens as possible, each of whom has a tiny drop of it. This way, there is even more resilience than in a plutocracy or in an oligarchy. The hope is that millions of drops of informed self-interested choices may translate into rational delegation to, and control of, those who will govern. Clearly, the larger the number of drops, the more robust the equilibrium becomes. The result is that those who can empower, that is, the electorate, must be able to delegate, check, criticise, and re-delegate those they empower, by debating and voting freely, rationally, tolerantly, and informatively, on what matters to the res publica. This is where structuralism and proceduralism join forces. And they should do so on the basis of some kind of "human project", that is, an evaluation of what would be a good polity. This is where structuralism joins forces with substantialism and its values. But if the manipulation of the aggregation of votes (consent), especially through mass media, ends up coagulating the drops into populist waves, and if the waves are allowed to exercise their power directly, without any constraints (e.g. it is common to require a two-thirds majority for 
major constitutional changes), then one faces the very serious risk of ending up in a form of dictatorship, the "tyranny of the majority" (Adams 1787). Direct democracy, whether digitally implemented or not, is much closer to dictatorship than representative democracy ever can be because its chance of escaping fascism is by relying hugely on the informed and rational nature of citizens' choices. And this is an idealism that cannot be trusted. Too often, the outcome is tragic choices and irretrievable damages: Jesus instead of Barabbas, leave instead of remain. It is not accidental that all forms of dictatorship have always been keen on plebiscites.

This leads me to the second lesson. We just saw that citizens can play their political role all the better the more they are informed, not only on the issues under discussion, but also about whom they are electing, how trustworthy, capable, and committed to improving the common good they are, and how they intend to manage their delegated power to the benefit of the whole res publica. Digital technologies should be a great engine of civic information, to get a clear idea of how things are, free from humbug, and to unmask those unworthy of political leadership, the Berlusconis, Farages, Johnsons, Le Pens, Putins, and Trumps of this world. Transparency and accountability can be much better guaranteed in a mature information society. Unfortunately, this is not always the case, to put it kindly. It certainly was not the case in Britain during the referendum campaign, where a divided political class, having cowardly re-delegated back to the citizens the very difficult and complex political decision about whether to leave the European Union, then resorted to demagoguery and populism to influence them, contributing to the expansion of media echo chambers, with little dialogue or real information. Once the mistake was made with the choice in favour of Brexit, no politician had the courage to remind the majority-now-raised-to-tyrant that the ultimate decision about Brexit still belonged to the parliament. As I write, it would still be possible to ignore the referendum, which in Britain is not legally binding. But the political class that has de-responsibilised itself by invoking the referendum certainly lacks the courage to re-take responsibility by ignoring it.

We come to the third lesson. History is not physics and does not know necessary laws. But, at the moment, it is plausible that Britain will invoke at some point article 50 and begin the process of leaving the European Union; hence, that Scotland will demand and likely win a new referendum on independence and attempt to start the process of joining the European Union as an independent country, and that England, Wales, and Northern Ireland may be perhaps all that will remain of the British Empire, a "Great England" which will have preferred to commit suicide rather than accept to become a normal European country. It might be a faster disintegration than Yugoslavia's; the last chapter in the decline and fall of just another empire. It will be financially painful, paradoxically especially for those who voted in favour of leaving the EU, but hopefully, it will also be largely non-violent and peaceful. A modest advantage of such a tragic implosion would be the possibility of a more viable European political project. Politics should not only be based on economic policies (necessary condition). It should be mainly driven by a human and social project (sufficient condition). The European Union cannot be made only of laws and regulations, subsidies, grants, and funds, the euro or a common market. It must be first and foremost a project of social coexistence that is value-adding: being together must be better than being alone. The shape of such a political project for a future European Union will require some very smart designing, remarkable politicians, and a wise and well-informed electorate. Not a likely scenario. But without the UK desperately 
pulling the break, it may finally be just a bit less difficult to bring together the European mosaic, probably under the leadership of Germany. In this case too, digital technologies will be essential in order to engage all Europeans in the construction of a better EU. The post-Brexit era could start from a "Europe of networks".

\section{References}

Adams, J. (1787). A defence of the constitutions of government of the United States of America. London: C. Dilly. Bobbio, N., \& Bellamy, R. (1987). The future of democracy: a defence of the rules of the game. Cambridge: Polity. Mill, J. S. (1861). Considerations on representative government. London: Parker, Son, and Bourn. Pennock, J. R. (1979). Democratic political theory. Princeton: Princeton University Press. Thorley, J. (2004). Athenian democracy. London: Routledge.

Wolf, M. (2016). Brexit will reconfigure the UK economy. Financial Times. 